\title{
MESENTERIC HYDATID CYST: AN UNUSUAL PRESENTATION
}

\author{
Sandhya Mittal, MBBS, DGO', Bal Krishan Taneja, MBBS, MD', Anupama Goel, MBBS, MD', \\ Meenu Puri, MBBS'1, Pinky Pandey, MBBS, MD² \\ Departments of ${ }^{1}$ Obstetrics and Gynecology, ${ }^{2}$ Pathology, Maharishi Markandeshwar Institute of Medicial Sciences and Research (MMIMSR), Mullana (Ambala), \\ Haryana, India
}

Hydatidosis is a common zoonosis that affects a large number of humans and animals, especially in poorly developed countries. Mesenteric hydatid cysts are rare intra abdominal lesions with variable clinical symptoms and signs that make preoperative diagnosis difficult. The treatment is surgical excision followed by mebendazole for four months. We report this unusual case where preoperative diagnosis of right tubo-ovarian mass was made and the diagnosis of mesenteric hydatid cyst could be made only on laprotomy and microscopic examination after surgery.

Keywords: Hydatidosis; Laprotomy; Mesenteric Hydatid cyst; Tubo ovarian mass

Hydatid disease is a zoonotic infection caused by larval stages of cestode Echinococcus granulosus (family taeniidae) and rarely by Echinococcus multilocularis. Dogs and other carnivores are definitive hosts where as sheep and ruminants are intermediate hosts. Man becomes an accidental host by consuming vegetables and water contaminated with hydatid ova. Although liver (75\%) and lung $(15 \%)$ are the most commonly involved organs, the disease can be seen anywhere in the body (10\%) [1,2]. Bickers [3] after reviewing 532 cases of hydatid disease from an endemic area over a 20 year period recorded only 12 instances of hydatid cyst in pelvis.

\section{Case Report}

A 35-year-old lady para two live two presented with pain lower abdomen for two years. The pain was dull in nature. There was no change in her bowel and bladder habits. She was para two live two and was using barrier contraceptive. Her menstrual cycle was regular. On physical examination vitals were stable. Her abdominal examination was unremarkable. On per speculum examination cervix and vagina was healthy. Per vaginum examination revealed normal size anteverted uterus deviated to left side. The mobility of the uterus was restricted. A large cystic mass measuring about
$6 \times 6 \mathrm{~cm}$ was palpable in the right fornix which was adherent to the uterus. Left adnexa were normal. On per rectal examination there was no nodularity in the pouch of Douglas and rectal mucosa was free. The routine laboratory investigations were within normal limits. X-ray chest and ultrasound (USG) upper abdomen was normal. USG lower abdomen and pelvis showed normal size uterus with a large multicystic septated mass in the right adnexa measuring $11 \times 7 \mathrm{~cm}$. Left adnexa was normal. Her CA-125 was normal. Diagnosis of right adnexal cyst was made and she was planned for exploratory laprotomy. Intra operatively a cyst measuring $10 \times 6 \mathrm{~cm}$ was seen arising from the mesentery and was

Received: 2012.1.9. Revised: 2012.3.18. Accepted: 2012.4.10.

Corresponding author: Sandhya Mittal, MBBS, DGO

Department of Obstetrics and Gynecology, Maharishi

Markandeshwar Institute of Medicial Sciences and Research

(MMIMSR), 344/5 Urban Estate, Kurukshetra, Haryana 136118, India

Tel: +91-1744-232886 Fax: +91-1744-232886

E-mail: sandhya81969@yahoo.com

This is an Open Access article distributed under the terms of the Creative Commons Attribution Non-Commercial License (http://creativecommons.org/licenses/ by-nc/3.0/) which permits unrestricted non-commercial use, distribution, and reproduction in any medium, provided the original work is properly cited.

Copyright $\odot$ 2012. Korean Society of Obstetrics and Gynecology 


\section{KOREAN JOURNAL OF OBSTETRICS \& GYNECOLOGY}

Sandhya Mittal, et al. A rare case of mesenteric hydatid cyst

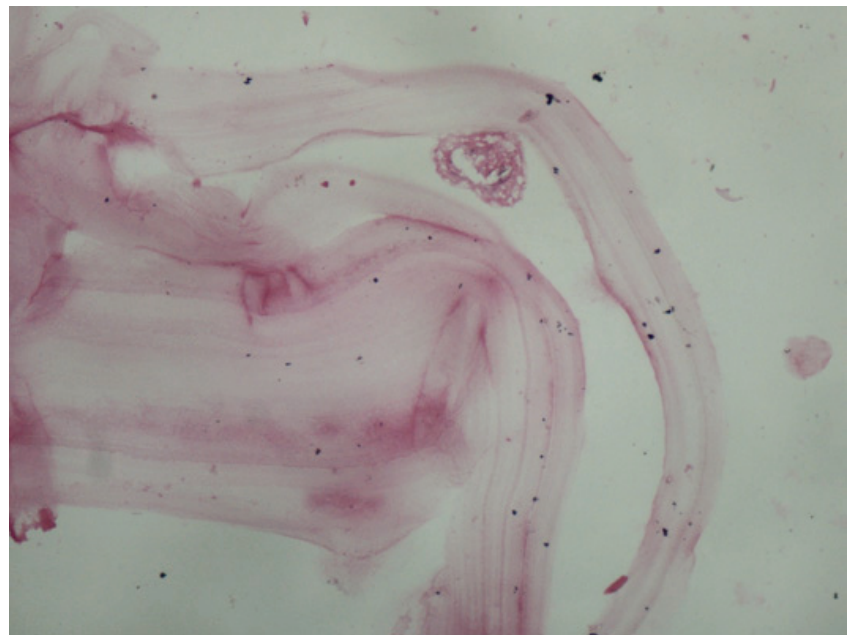

Fig. 1. Photomicrograph showing acellular laminated ectocyst and a single scolex $(H \& E, \times 200)$.

found to be badly adherent to the right ovary, fallopian tube and posterior surface of uterus and it could not be separated from the uterus and ovary. Removal of mesenteric cyst and right salpingoophorectomy was planned but total abdominal hysterectomy was also done as patient insisted on it. The whole specimen was sent for histopathological examination. Cut sections of mesenteric cysts showed glistening white multiple daughter cysts and microscopic examination revealed scolices with hook lets of Echinococcus granulosus (Fig. 1).

Cervix, right ovary and fallopian tube were unremarkable. Microscopic examination of uterus showed simple endometrial hyperplasia and myometrium was unremarkable. On taking history retrospectively it was found that infection was probably accidently acquired in our patient, there was no history of pets nor a visit to an endemic area. Patient recovered well and was discharged on the tenth postoperative day with albendazole $(10 \mathrm{mg} / \mathrm{kg}$ bodyweight/day) for six months.

\section{Discussion}

Mesenteric hydatid cyst is the most unreported site so far as literature goes. There are rare lesions with prevalence of 1:100,000 in adults and 1:20,000 in children [4]. Hydatid disease is endemic in cattle grazing areas particularly Australia, New Zealand, Middle East, India, South America, and Turkey [5]. Most common locations of hydatid cyst are liver and lungs but unusual locations such as brain, heart, pericardium, kidney, intraperitoneum, retroperitonium, bone, soft tissue and breast have been reported in literature. Extra hepatic localization frequently occurs after hepatic involvement. Primary peritoneal echinococcosis is very rare and has been reported to occur in $2 \%$ of all abdominal hydatid diseases [6]. Clinical manifestations vary with the site and size of the cyst which ranges between a few centimeters and ten centimeters and symptoms are due to space occupying effect within organs or systemic reactions due to perforation. Fortunately they behave mostly as benign tumors, while malignancy accounts for $2 \%$ of cases [4].

The correct preoperative diagnosis of hydatidosis is difficult due to its rarity, lack of specific symptoms, diverse imaging appearances and striking resemblance between hydatid cyst and malignant disease of the related organ. Singh et al. [7] reported a case of primary hydatidosis of female genital tract for which pre operative diagnosis of malignant ovarian cyst was made and total abdominal hysterectomy with bilateral salpingo-oopherectomy was done. The diagnosis of hydatid cyst adherent to uterus and adnexa was made after histopathological examination. Okumuş et al. [8] also reported a case in which the primary involvement was of the uterus but the diagnosis was confirmed only by microscopic study after surgery. However the diagnosis may be possible by clinical finding, imaging studies and laboratory tests including echinococcal titers. The imaging modality of choice is abdominal ultrasonogaphy. Computed tomography scan can reveal that the cyst is not arising from other organs like kidney, pancreas or ovary [9]. Surgery along with postoperative albendazole or mebendazole therapy is the treatment of choice for primary abdominal hydatid disease. It has been suggested that preoperative course of albendazole should be considered in order to sterilize the cyst, decrease the chances of anaphylaxis, decrease the tension in the cyst wall (thus reducing the risk of spillage during surgery) and to reduce the recurrence rate postoperatively $[10,11]$.

Thus, we conclude that isolated mesenteric cyst is a unique manifestation of hydatid disease. Infection was probably accidently acquired in our patient, there was no history of pets nor a visit to an endemic area. Owing to its rarity in area other than endemic areas and variable imaging appearances preoperative diagnosis of peritoneal/mesenteric hydatid disease is a clinical challenge so a suspicion of this disease is justified in all patients presenting with cystic mass especially in endemic areas.

\section{References}

1. Bourée P. Hydatidosis: dynamics of transmission. World I Surg 2001;25:4-9. 


\section{KOREAN JOURNAL OF OBSTETRICS \& GYNECOLOGY}

KJOG Vol. 55, No. 5, 2012

2. Engin G, Acunaș B, Rozanes I, Acunaș G. Hydatid disease with unusual localization. Eur Radiol 2000;10:1904-12.

3. Bickers WM. Hydatid disease of the female pelvis. Am J Obstet Gynecol 1970;107:477-83.

4. Theodoridis TD, Zepiridis L, Athanatos D, Tzevelekis F, Kellartzis D, Bontis JN. Laparoscopic management of mesenteric cyst: a case report. Cases I 2009;2:132.

5. Pedrosa I, Saíz A, Arrazola J, Ferreirós J, Pedrosa CS. Hydatid disease: radiologic and pathologic features and complications. Radiographics 2000;20:795-817.

6. Atin H, Shyamapada P, Khaled, Saswati H. An unususal case of hydatid cyst of the ovary and pouch of douglas. J Obstet Gynecol India 2010;60:343-4.

7. Singh AP, Sikarwar S, Shrivastava BR, Gupta S, Sultana K.
Primary hydatidosis of female genital tract: a case report. J Indian Med Assoc 2009;107:169-70.

8. Okumuș Y, Tayyar M, Patiroğlu T, Aygen E. Uterine hydatid cyst. Int J Gynaecol Obstet 1994;45:51-3.

9. Alis H, Kapan S, Öner O, Soylu A, Dolay K, Kalayci MU, et al. Primary omental hydatid cyst. Int Med Case Reports J 2009;1:7-10.

10. Guidelines for treatment of cystic and alveolar echinococcosis in humans. WHO Informal Working Group on Echinococcosis. Bull World Health Organ 1996;74:231-42.

11. Gourgiotis S, Stratopoulos C, Moustafellos P, Dimopoulos N, Papaxoinis $G$, Vougas $V$, et al. Surgical techniques and treatment for hepatic hydatid cysts. Surg Today 2007;37:389-95. 